\title{
VIRTUAL AUTOPSY: A NEW TREND IN FORENSIC INVESTIGATION
}

\author{
Ahmad $\mathrm{M}^{1}$, Rahman $\mathrm{FN}^{2}$
}

\begin{abstract}
Introduction: The modern high-resolution imaging has been used as a well described aid in the setting of post-mortem investigations. In developed countries Computed Tomography (CT) and Magnetic Resonance Imaging (MRI) are now being evaluated as complementary means for cause-of-death determination.
\end{abstract}

Objective: This paper explores the implication of virtual autopsy from ethical and technical point of view.

Methods: Published literature with strict inclusion and exclusion criteria were extensively reviewed through use of general and Meta search engines to elucidate the applications and implications of virtual autopsy.

Discussion: Virtual autopsy introduces a new era in autopsy examination. It utilizes the technological innovation of modern imaging system to obtain high quality 3 Dimensional images of the body in multiple plains without mutilation of the human body. The Virtual Autopsy can be applied in a broad number of forensic situations, such as thanatological investigations; carbonized and putrefied body identifications; mass disaster cases; age estimation; anthropological examinations and skin lesion analyses, determining cause of death determination; decedent gender, identification in difficult forensic cases; body length and Individual decedent feature identification; identifying distinct foreign bodies - retained bullets, blades, etc.; identification of injuries and forensic reconstructions - three dimensional reconstructions, bullet tract identification; education and clinical performance improvement process; and research.

Conclusion: Due to its minimal invasive procedure, virtual autopsy is very much acceptable to the society. In USA and European countries virtual autopsy is likely to replace conventional autopsies in future. We can also utilize this modern technology to upgrade the century old investigation system in our country.

Key-words: Virtual autopsy, Conventional post mortem examination, Future aspect.

\section{Introduction}

The modern high-resolution imaging has been used as a well described aid in the setting of post-mortem investigations. In developed countries Computed Tomography (CT) and Magnetic Resonance Imaging (MRI) are now being evaluated as complementary means for cause-of-death determination.

1. Lt Col Mushtaq Ahmad, MBBS, DFM, MCPS, Associate Professor \& Head, Dept of Forensic Medicine and Toxicology, Armed Forces Medical College, Dhaka; 2. Dr. Farial Naima Rahman, MBBS, DMU. Lecturer, Dept of Forensic Medicine and Toxicology, Armed Forces Medical College, Dhaka. 


\section{Objective}

This paper explores the implication of virtual autopsy from ethical and technical point of view. In this article the history of autopsy and the reasons for the gradual decrease in conventional autopsy rates over the last two decades have been briefly described. An overview on advantages and limitations of modern imaging autopsy techniques is also presented and potential future applications of modern imaging techniques in postmortem analysis are also discussed.

\section{Materials and Methods}

Published literature with strict inclusion and exclusion criteria were extensively reviewed through use of general and Meta search engines to elucidate the applications and implications of virtual autopsy. Articles containing information regarding the history of virtual autopsy, its application in different cases, and gradual development of the procedures in western countries and future aspects of this method have been taken into count for collection of data and references.

\section{Discussion}

The word "autopsy" has come from the Greek words - "Autos"- which means self and "opis" which means view or to see for one self. It is also called necropsy. ("Necros" means- dead body) or post mortem examination ("post"- means after, "mortem" means death) ${ }^{1}$. Autopsy is a special type of scientific examination of a dead body carried out under the law of state. A model autopsy procedure has been produced by United Nations within the context of investigation of human rights abuses called the-'Minnesota Protocol ' (The United Nations Manual on the Effective presentation and investigation of extra legal, arbitrary and summary execution). It can be used to deal with difficult, controversial or sensitive cases ${ }^{2}$. The first medico legal autopsy was done by Bartolomio De Varignana ${ }^{3}$ in Italy in 1302. In this Subcontinent the first medico legal autopsy in India was performed by $\mathrm{Dr}$ Edward Bulkley ${ }^{4}$ on 28th August 1693. Mainly autopsy are of three types: medico legal, pathological or clinical or hospital and anatomical ${ }^{5}$.
In most countries, clinical autopsies are performed with permission from the family of the deceased. As a consequence of its invasiveness, permission to conduct a clinical autopsy is often not given ${ }^{6-8}$. In ancient Egypt and Mesopotamia postmortem dissections were frequently performed during the process of embalming. In India, autopsy and dissection were practiced by Sushruta, an early pioneer of ayurveda (the Indian art of medicine) in the sixth century B.C. In the third century B.C., Greek scholars used autopsy for the purpose of enhancing their understanding of anatomy and disease. Similar approaches re-emerged in Europe during the middle Ages and the Renaissance with the work of Vesalius and others. The first organized treatise on pathological findings at autopsy was "The seats and causes of diseases investigated by anatomy", published in 1761 by Giovanni Batista Morgagni when he was 79 years old. This book, describing nearly 700 autopsies performed by the author, is the foundation of modern post-mortem science. At the end of the nineteenth century, Osler established autopsy as one of the cornerstones of his approach to both medical training and clinical method ${ }^{9-11}$. In the first half of the twentieth century autopsy rates steadily increased. In the 1960's and 1970's, many of the advances in cardiovascular surgery developed by DeBakey and his team were pioneered using cadaveric testing. The second half of the 20th century and the beginning of 21st century saw continued decline in autopsy rates. This was largely a global phenomenon, with only a few countries where autopsy rates remained relatively constant or decreased less dramatically, including Sweden and Finland ${ }^{12-13}$. Over the past three decades, there has been a $40-50 \%$ drop in autopsy rates across the world ${ }^{14}$. In the United States, autopsy rates fell from the reported high of $41 \%$ in the 1960 's to between $5 \%$ and $23 \%$ at present ${ }^{15-16}$. The most commonly cited factors accounting for this phenomenon include physician discomfort in requesting permission from the family, cost containment measures, risk of blood borne pathogen transmission, as well as the perceived absence of the curricular/educational value of autopsies $^{17-21}$. 
One report from Australia demonstrated a sharp drop in autopsies from nearly $40 \%$ in the year 2000 to just over $10 \%$ in 2001 which was attributed to a significant increase in autopsy refusals ${ }^{22}$. The Virtopsy, or "virtual autopsy" was developed by Richard Dirnhofer, former Director of Forensic Medicine, Berne, which was then continued by his successor, Michel Thali and his colleagues at the University of Berne's Institute of Forensic Medicine, Switzerland. During autopsy the 3-D geometry of human body is destroyed but using the cross-section imaging technique, it is possible to document the same findings in a noninvasive way. A multi-slice computed tomography (MSCT) and magnetic resonance imaging (MRI) -visualize the interior of the body for collection of all the data in details in regards to condition of different organs. Specific software (e.g. Tera Recon Aquarius NET $®$, Foster City, California, United States of America) allowed for 3D reconstructions of the computed tomography images from the observed structures. Another part of the documentation concerns the body surface recording, performed by forensic photogrammetric and $3 \mathrm{D}$ optical scanning. One can examine the part of the body slice by slice in different planes according to the requirement of the situation. Apart from these, using the magnetic resonance imaging spectroscopy, time since death can also be estimated by measuring metabolites in the brain, emerging during postmortem decomposition. The samples for histopathological examination if required can be collected more precisely using CT guided needle biopsy. Postmortem angiography is used to visualise the cardiovascular system ${ }^{23-26}$.

In 1980, Flodmark et al performed a comparison study of premortem computed tomographic findings and subsequent autopsy results in neonates who suffered perinatal asphyxia ${ }^{27}$. Kalender et al followed in 1990 by developing acquisition and processing of three-dimensional digital radiographic imaging data ${ }^{28}$. The 1990 's saw the inception of large-scale research programs dedicated to imaging autopsy. The most prominent of those programs is the Virtopsy Project at the University of Bern, Switzerland. Other programs include those headed by Donchin et $\mathrm{al}^{29}$, military- sponsored programs in the USA ${ }^{30}$, and the CATopsy program at St Luke's Hospital in Bethlehem, Pennsylvania, USA. R A L Bisset et $\mathrm{al}^{31}$ studied 53 cases at Manchester, UK in the year 1997, using MRI where the findings were confirmed by conventional autopsy. According to their study, the findings were more or less similar in both the methods. In their study, they could detect cardiac ischemia, pneumonic consolidations, pleural effusion or pulmonary oedema etc apart from the other cases. In Japan, postmortem computed tomography (PMCT) is widely applied for three major roles -screening the cause of death, screening candidates for autopsy, and for guidance and/or supplemental information for autopsy.

In a study conducted in Japan, questionnaire sheets were distributed, regarding the use of PMCT, to 183 major medical establishments having Emergency Rooms. Of these, 67\% responded and it was found that $89 \%$ of the respondents used PMCT. This high rate was likely because the number of CTs in Japan was greater than 10,000 units, constituting more than one-third of those world wide ${ }^{32}$. Since 2005, United States Army Forces Institute of Pathology has scanned and analyzed about 800 bodies killed in war zones in order to determine cause of death and examine the injuries ${ }^{33-35}$. This information will eventually be used to improve head and body armor and to improve combat casualty care. The Virtual Autopsy can be applied in a broad number of forensic situations, such as thanatological investigations; carbonized and putrefied body identifications; mass disaster cases; age estimation; anthropological examinations and skin lesion analyses, determining cause of death and decedent gender, identification in difficult forensic cases, body length and Individual decedent feature identification; identifying distinct foreign bodies retained bullets, blades, etc.; identification of injuries and forensic reconstructions - three dimensional reconstructions, bullet tract identification; education and clinical performance improvement process; and research - from medical to historical (i.e., mummies, etc) ${ }^{36}$. 
Thali et $\mathrm{al}^{37}$ have shown that virtual autopsy in gunshot wound victims is useful to localize the bullet in three dimensions, document the bullet path, visualize fracture patterns associated with gunshot wounds, and evaluate internal organ injury prior to autopsy. In 1977, Wullenweber et al reported one of the earliest forensic applications of computed tomography to describe radiographic patterns of gunshot injuries to the head ${ }^{38}$. In mass disaster cases Dirnhofer et $\mathrm{al}^{39}$ describe for human identification purposes the use of adapted vehicles (e.g. Oshkosh Specialty Vehicles $®$, Clearwater, Florida, United States of America) with imaging machines allowing for PM data collection on the disaster field. The author states that mobile CT imaging could provide a high level of positive identifications. In the odontology field Oesterhelweg et $\left.a\right|^{40}$ described a case where the victim was struck by respiratory obstruction from a foreign body (food bolus). Birngruber et $\mathrm{al}^{41-42}$ reported a positive identification case based on the superimposition of post-mortem CT reconstructed images on ante-mortem radiographies. Dedouit et $\mathrm{al}^{43}$ stressed the importance of the presence of dentists in the forensic identification team in particular to determine the age of charred bodies. Other studies ${ }^{44-47}$ also relates the role the forensic odontologist on age estimations.

In one study over $40 \%$ of postmortem CT studies revealed clinically significant findings that were not identified on traditional autopsy. IA offers excellent accuracy, including very close estimation of solid organ weights ${ }^{48}$. Imaging autopsies provide visualization of soft tissue patterns in cases of severe putrefaction. Aghayev et al described the use of both MSCT and MRI to document herniation of cerebellar tonsils prior to traditional autopsy in patients with blunt head injuries ${ }^{49}$. The same group also advocated postmortem imaging as a good forensic visualization tool for documentation and examination of traumatic injuries and other pathologic findings in a broad range of scenarios ${ }^{50}$. Oyake et al conducted an IA study to help determine the etiology of sudden death due to non-traumatic causes in infants and children.
Imaging autopsies in that study were able to point to the cause of death in 14 of 15 decedents when radiographic information was combined with premortem clinical and laboratory data ${ }^{51}$. In 2007, Levy et al published a series of postmortem CT examinations of military air mishap victims. In that study, pockets of ectopic air in various anatomic areas were found in $24 \%$ of victims. They also noted that detection of solid organ injury and superficial traumas were significantly worse on CT than on a traditional autopsy, corroborating the complementary character of IA studies ${ }^{52}$. In hanging cases the $C T$ images of the injuries of the neck obtained by CT scan clearly showed the ligature mark, the hemorrhagic suffusion in the soft tissue (thickening of derma) and in the muscles (sternocleidomastoid) of the neck. Furthermore, CT 3-dimensional reconstruction showed brain edema, fracture of the left posterior horn of the hyoid bone, and a grade 1 retrolisthesis of $\mathrm{C} 5$ on C6. In drowned bodies the CT information about the volume, density, size of the lungs and the amount of liquid observed in them is helping in diagnosing the cause of death ${ }^{53}$.

The data is stored in digital format, so can be transmitted to any part of the world and easily transferred to courtrooms and because they offer a less gruesome alternative to traditional autopsy photographs, less time consuming and body can be released immediately after the scanning, better acceptance for the relatives of the diseased and also by the religious customs as incisions are not used. The disadvantages of this procedure includes: insufficient data base of comparative study of virtopsy and conventional autopsy. It is not possible to distinguish all the pathological conditions with this technique, cannot give the infection status, difficult to differentiate antemortem or the postmortem wounds, difficult to appreciate the postmortem artifacts, difficult to appreciate the colour changes, small tissue injury may be missed and in our scenario, it is not possible to provide these types of investigations to all the living persons. 


\section{Conclusion}

Virtual autopsy introduces a new era in autopsy examination. It utilizes the technological innovation of modern imaging system to obtain high quality 3Dimensional images of the body in multiple places without mutilation of the human body. It also incorporates other minimally invasive techniques such as image guided biopsy, MR spectroscopy, postmortem angiography etc. followed by data analysis to give a postmortem diagnosis. Due to its minimal invasive procedure, it is very much acceptable to the society. In USA and European countries virtual autopsy is likely to replace conventional autopsies in future. We can also utilize this modern technology to upgrade the century old investigation system in our country.

\section{References}

1. Biswas G. Review of Forensic Medicine \& Toxicology. 2nd ed. New Delhi :Jaypee : 2012. p 83-5.

2. James JP, Jones R, Karch SB, Manlove J. Simpson's Forensic Medicine 13th ed.London: Arnold: 2011. p31-4.

3. Reddy KSN. The Essentials of Forensic Medicine \& Toxicology. 31st ed. Hyderabad : Medical Book Coy :2012. p 1-7.

4. Mathiharan K, Patnaik AK. Modi;s Medical Jurisprudence and Toxicology. 23rd ed. : Butterworts :. 2005. p1-8.

5. Rao NG. Text book of Forensic Medicine \& Toxicology. 2nd ed. New Delhi :Jaypee: 2010. p162-4.

6. Burton JL. A bite into the history of the autopsy. Forensic Science, Medicine, and Pathology 2005;1: 277-84.

7. Pathology. Wikipedia. Available at: http://en.wikipedia.org/wiki/ Pathology\#_note-0. Last accessed on June 21, 2013.
8. Scholing M. , Saltzherr T. P. , Fung Kon Jin P. H. P. , Ponsen K. J., Reitsma J. B. , Lameris J. S. , Goslings J. C. . The value of postmortem computed tomography as an alternative for autopsy in trauma victims: a systematic review Eur Radiol. 2009 October; 19(10): 2333-41.

9. Rodin AE. Osler's autopsies: their nature and utilization. Med Hist 1973;17:37-48.

10. Hill RB, Anderson RE. The recent history of the autopsy. ArchPathol Lab Med 1996;120:702-712.

11. Rutty G. Are autopsies necessary? The role of computed tomography as a possible alternative to invasive autopsies. Rechtsmedizin 2007;17:21-8.

12. Saukko P. Medicolegal investigative system and sudden death in Scandinavia. Nihon Hoigaku Zasshi 1995;49:458-65.

13. Lindstrom P, Janzon L, Sternby NH. Declining autopsy rates in Sweden: a study of causes and consequences in Malmo, Sweden. J Intern Med 1997;242:57-165.

14. Loughrey MB, McCluggage WG, Toner PG. The declining autopsy rate and clinicians' attitudes. Ulst Med J 2000;69:83-9.

15. Burton EC, Phillips RS, Covinsky KE, Sands LP, Goldman L, Dawson NV, Connors AF Jr, Landefeld CS. The relation of autopsy rate to physicians' beliefs and recommendations regarding autopsy. Am Journal Med 2004;117:255-61.

16. Corona T, Rembao D, Sotelo J. Improving the autopsy rate in a teaching hospital. Arch Pathol Lab Med 2003;127:1408-1409.

17. Grossman MD, Stawicki SP. The impact of human immunodeficiency virus (HIV) on outcome and practice in trauma: Past, present, future. Injury 2006;37:1117-24. 
18. Lundberg GD. Medicine without the autopsy. Arch Pathol Lab Med 1984;108:449-54.

19. O'Grady G. Death of the teaching autopsy. BMJ 2003;237:802-3.

20. Welsh TS, Kaplan J. The role of postmortem examination in medical education. Mayo Clin Proc 1998;73:802-5.

21. Combes A, Mokhtari M, Couvelard A, Trouillet $\mathrm{JL}$, Baudot J, Hénin $\mathrm{D}$, et al. Clinical and autopsy diagnoses in the intensive care unit: a prospective study. Arch Intern Med. 004;164:389-92.

22. Ward HE, Clarke BE, Zimmerman PE, Cleary MI. The decline in hospital autopsy rates in 2001. MJA 2002;176:91.

23. Thali MJ, Yen K, Vock P, Ozdoba C, Kneubuehl BP, Sonnenschein M \& Dirnhofer R. Image-guided virtual autopsy findings of gunshot victims performed with multi-slice computed tomography and magnetic resonance imaging and subsequent correlation between radiology and autopsy findings, Forensic Sci Int. 2003 Dec 17;138(1-3):8-16.

24. Thali MJ, Braun M, Buck U, Aghayev E, Jackowski C, Vock P, Sonnenschein M \& Dirnhofer R. VIRTOPSY-scientific documentation, reconstion and animation in forensic: individual and real 3D data based geometric approach including optical body/object surface and radiological CT/MRI scanning, J Forensic Sci. 2005 Mar;50(2):428-42.

25. Dirnhofer R, Jackowski C, Vock P, Potter K \& Thali MJ. VIRTOPSY: minimally invasive, imaging-guided virtual autopsy. Radiographics, 2006 Sep-Oct;26 (5):1305-33.

26. Buck $U$, Naether $S$, Braun $M$, Bolliger $S$, Friederich H, Jackowski C, Aghayev E,Christe A, Vock P, Dirnhofer R \& Thali MJ.Application of 3D documentation andgeometric reconstruction methods in traffic accident analysis: with high resolution surface scanning, radiological MSCT / MRI scanning and real data based animation. Forensic Sci Int, 2007 Jul 20;170 (1):20-8.
27. Flodmark O, Becker LE, Harwood-Nash DC, Fitzhardinge PM, Fitz CR, Chuang SH. Correlation between computed tomography and autopsy in premature and full-term neonates that have suffered perinatal asphyxia. Radiology. 1980;137:93 -103.

28. Kalender WA, Seissler W, Klotz E, Vock P. Spiral volumetric CT with single-breath-hold technique, continuous transport, and continuous scanner rotation. Radiology 1990;176:181-183.

29. Donchin Y, Rivkind Al, Bar-Ziv J, Hiss J, Almog $\mathrm{J}$, Drescher M. Utility of postmortem computed tomography in trauma victims. J Trauma 1994;37:552-555.

30. Levy AD, Abbott RM, Mallak CT, Getz JM, Harcke HT, Champion HR, Pearse LA. Virtual autopsy: preliminary experience in highvelocity gunshot wound victims. Radiology 2006; 240: 522.

31. Bisset R A, Thomas N B , Turnbull \& Lee S. Postmortem examinations using magnetic resonance imaging: Four year review of a working service. BMJ,2002;324:1423-1424.

32. Thali MJ, Barun M \& Dirnhofer R. Optical 3D surface digitizing in Forensic Medicine: 3D Documentation of skin and bone injuries, Forensic Sci Innt, 2003,Nov26:137(2-3):203-8.

33. Hayakawa M, Yamamoto S, Motani H, Yajima $D$, Sato $Y$, Iwase $H$. Does imaging technology overcome problems of conventional postmortem examination? A trial of computed tomography imaging for postmortem examination. Int $\mathrm{J}$ Legal Med 2006;120:24-26.

34. Thali MJ, Braun M, Buck U, Aghayev E, Jackowski C, Vock P, Sonnenschein M, Dirnhofer R. Virtopsy - scientific documentation, reconstruction and animation in forensic: individual and real 3Dmdata based geo-metric approach including optical body/object surface and radiological CT/MRI scanning. J Forensic Sci 2005;50:428-42. 
35. Levy AD, Harcke HT, Getz JM, Mallak CT, Caruso JL, Pearse L, Frazier AA, Galvin JR. Virtual autopsy: Two- and three-dimensional multidetector CT findings in drowning with autopsy comparison. Radiology 2007;243:862-8.

36. Paperno S, Riepert T, Grug B, Rotschild MA, Schultes A, Staak M, Lackner L. Value of postmortem computed tomography in comparison to autopsy. Rofo 2005;177:130-6.

37. Thali MJ, Yen K, Plattner T, Schweitzer W, Vock P, Ozdoba C, Dirnhofer R. Charred body: virtual autopsy with multi-slice computed tomography and magnetic resonance imaging. J Forensic Sci 2002;47:1326-1331.

38. Wullenweber R, Schenider V, Grumme T. A computertomographical examination of cranial bullet wounds. Z Rechtsmed 1977;80:227-46.

39. Dirnhofer R, Jackowski C, Vock P, Potter K, Thali MJ. Virtopsy - minimally invasive, imaging guided virtual autopsy. Radio Graphics 2006;26:1305-33.

40. Oesterhelweg L, Bolliger SA, Thali MJ, Ross S. Postmortem imaging of laryngeal foreign bodies. Arch Pathol Lab Med 2010;133:806-10.

41. Levy AD, Abbott RM, Mallak CT, Getz JM, Harcke HT, Champion HR, Pearse LA. Virtualautopsy - Preliminary experience in high-velocity gunshot wound victims. Radiology 2006;240:522-8.

42. Birngruber CG, Obert M, Ramsthaler F, Kreutz $\mathrm{K}$, Verhoff MA. Comparative dental radiographic identification using flat panel CT. Forensic Sci Int 2011;209:31-4.

43. 43. Dedouit F, Telmon N, Costaglioga R, Otal $P$, Joffre $F$, Rougé D. Virtual anthropology and forensic identification: Report of one case. Forensic Sci Int 2007;173:182-7.

44. Dedouit F, Telmon N, Guilbeau-Frugier C, Gainza D, Otal P, Joffre F, Rougé D. Virtual autopsy and forensic identification - practical application: are port of one case. J Forensic Sci 2007;52:960-4.
45. Bassed RB, Hill AJ. The use of computed tomography (CT) to estimate age in the 2009 Victorian Bushfire Victims: a case report. Forensic Scilnt 2011;205:48-51.

46. . O'donell C, Lino M, Mansharan K, Leditscke $\mathrm{J}$, Woodford N. Contribution of post mortem multidetector CT scanning to the identification of the deceased in a mass disaster: experience gained from the 2009 Victorian bushfires. Forensic Sci Int 2011;205:15-28.

47. Cordner SM, Woodford N, Bassed R. Forensic aspects of the 2009 Victorian Bushfires Disaster. Forensic Sci Int 2011;205:2-7.

48. Jackowski C, Thali MJ, Buck U, Aghayev E, Sonnenschein M, Yen K, Dirnhofer R, Vock P. Noninvasive estimation of organ weights by postmortem magnetic resonance imaging and multislice computed tomography. Invest Radiol 2006;41:572-8.

49. Aghayev E, Yen K, Sonnenschein M, Ozdoba C, Thali M, Jackowski C, Dirnhofer R. Virtopsy post-mortem multi-slice computed tomography (MSCT) and magnetic resonance imaging (MRI) demonstrating descending tonsillar herniation: comparison to clinical studies. Neuroradiology 2004;46:559-64.

50. Aghayev E, Thali MJ, Jackowski C, Sonnenschein M, Dirnhofer R, Yen K. MRI detects hemorrhages in the muscles of the back in hypothermia. Forensic Sci Int 2008;176:183-6.

51. Oyake Y, Aoki T, Shiotani S, Kohno M, Ohashi $\mathrm{N}$, Akutsu H, Yamazaki K. Postmortem computed tomography for detecting causes of sudden death in infants and children: retrospective review of cases. Radiat Med 2006;24:493-502.

52. Levy G, Goldstein L, Blachar A, Apter S, Barenboim E, Bar-Dayan Y, Shamis A, Atar E. Postmortem computed tomography in victims of military air mishaps: radiological-pathological correlation of CT findings. Isr Med Assoc J 2007;9:699-702.

53. Polacco M, , Pasquale DA, Francesco, Bruno $Z$, et al. Virtual Autopsy in Hanging. American Journal of Forensic Medicine \& Pathology: June $2013: 34$ ( 2 ). 107-9. 